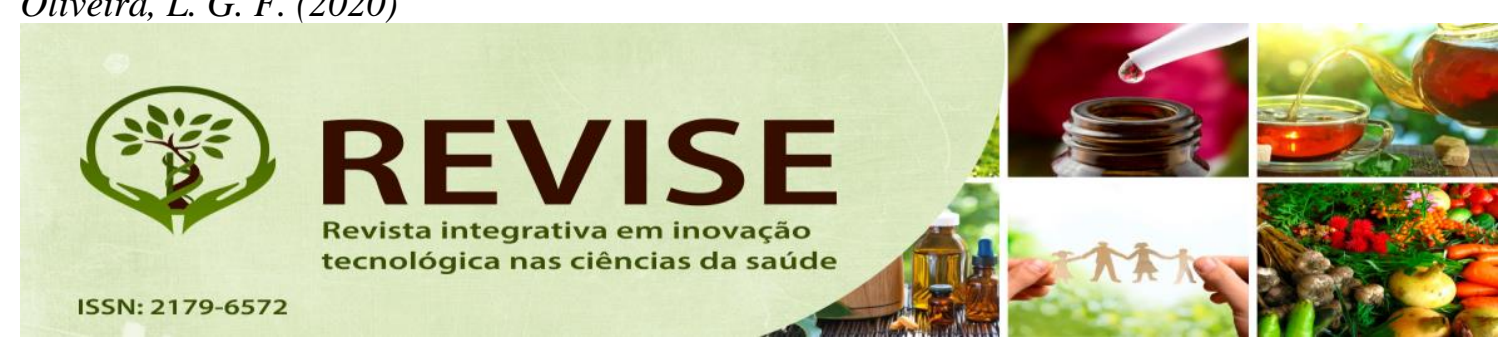

\title{
CONTRIBUIÇÕES DA EDUCAÇÃO EM SAÚDE PARA A GESTÃo EM SAÚDE COLETIVA
}

\section{CONTRIBUTIONS FROM HEALTH EDUCATION TO COLLECTIVE HEALTH MANAGEMENT}

Larayne Gallo Farias Oliveira UFSB/UESC

\begin{abstract}
RESUMO
Trata-se de uma revisão integrativa sobre as contribuições da educação em saúde para a gestão em saúde coletiva, pois essas práticas são uma aprendizagem no trabalho, em que o aprender e o ensinar se incorporam ao cotidiano das organizações deste trabalho. Este estudo buscou conhecer a produção científica sobre as contribuições da educação em saúde como ação estratégica dos modelos de Gestão em Saúde, assim como identificar estes modelos de gestão e estabelecer a relação dos modelos de Gestão em Saúde com a Educação em Saúde. Ela pode contribuir para a gestão em saúde ao passo que compreende a transformação da atenção à saúde possibilitando a incorporação de formas de relação com a população, profissionais de saúde e gestores, sendo um alicerce para gestão em saúde, pois elenca a construção da ação de saúde integralizada e apropriada às necessidades da população. Os dados alcançados permitiram conhecer parte da produção científica sobre as contribuições da Educação em Saúde como ação estratégica dos modelos de Gestão em Saúde visto que os entraves na construção deste estudo estiveram concentrados na limitação de artigos que refletem sobre a temática proposta. ${ }^{1}$
\end{abstract}

Palavras-chave: Educação em Saúde. Gestão em Saúde. Modelos de Gestão em Saúde.

\footnotetext{
${ }^{1}$ Esta pesquisa não recebeu financiamento.
} 


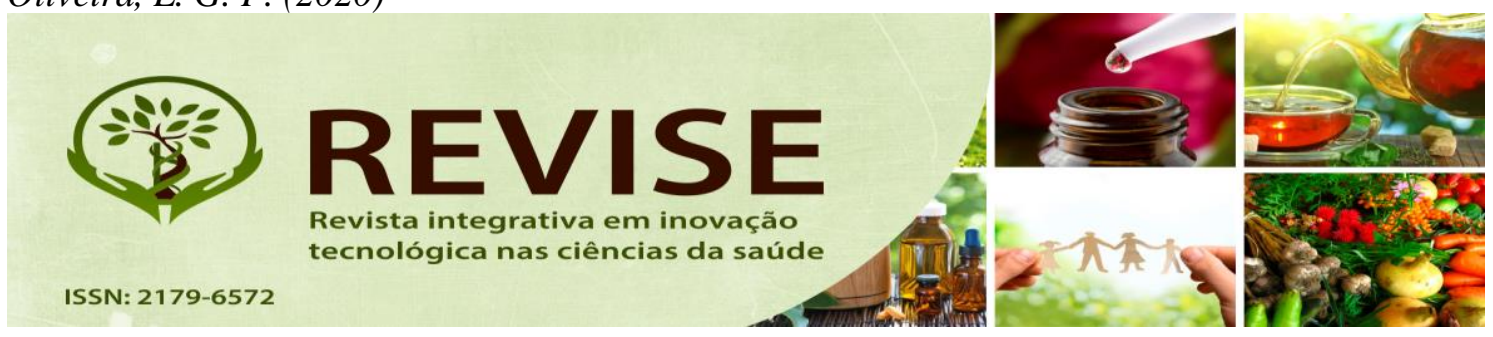

\begin{abstract}
This is an integrative review of the contributions of health education to colecctive health management, since these practices are learning at work, in which learning and teaching are incorporated into the daily life of the organizations of this work. This study sought to know the scientific production on the contributions of health education as a strategic action of Health Management models, as well as to identify these management models and to establish the relationship between Health Management models and Health Education. for health management, while it includes the transformation of health care, allowing the incorporation of forms of relationship with the population, health professionals and managers, being a foundation for health management, since it is the construction of integrated health action and appropriate to the needs of the population. The data obtained allowed to know part of the scientific production about the contributions of Health Education as a strategic action of Health Management models since the obstacles in the construction of this study were focused on the limitation of articles that reflect on the proposed theme.
\end{abstract}

Key words: Health Education. Health Management. Health Management Models.

\title{
INTRODUÇÃO
}

A educação em saúde representa um importante instrumento para se operacionalizar a construção de modelos de atenção em saúde que atendam às necessidades da gestão em saúde. Segundo Alves (2005), o modelo hegemônico de educação em saúde, em sua essência, divergente do princípio da integralidade, é caracterizado e discutido em comparação a um modelo de práticas de educação em saúde emergente, denominado neste ensaio de modelo dialógico, cuja lógica manteria coerência com a integralidade da atenção.

Besen et al. (2007) defendem que a prática da educação em saúde é uma aprendizagem no trabalho, em que o aprender e o ensinar se incorporam ao cotidiano das organizações deste trabalho. Propõe-se que os processos de capacitação dos trabalhadores da saúde tomem como referência as necessidades de saúde das pessoas e das populações e tenham como objetivos a transformação das práticas profissionais e da própria organização do trabalho, estruturadas a partir do processo de problematização. 


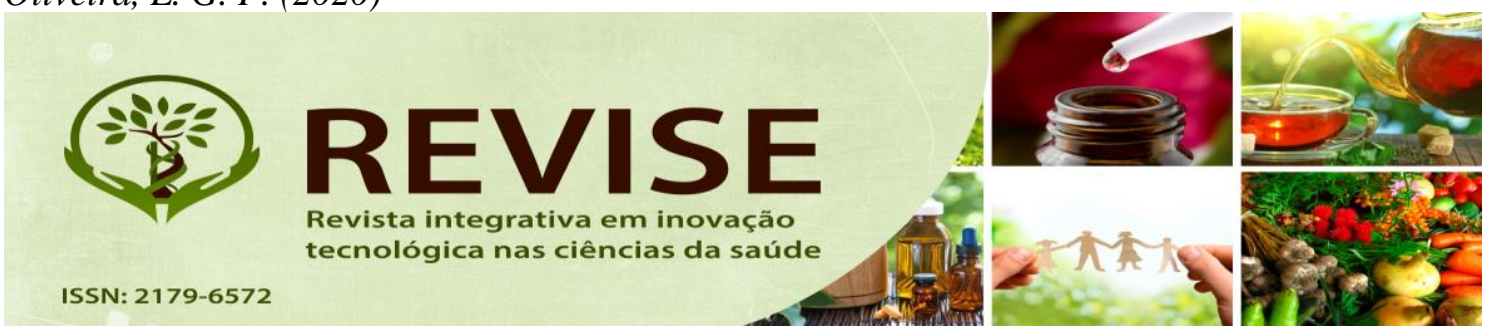

Sendo assim, como a educação em saúde pode contribuir para a gestão em Saúde? Ela pode contribuir para a gestão em saúde ao passo que compreende a transformação da atenção à saúde possibilitando a incorporação de formas de relação com a população e atores envolvidos (profissionais de saúde e gestores), sendo um alicerce fundamental para a Gestão em Saúde, pois elenca a construção da ação de saúde integralizada e mais apropriada às necessidades da população.

Portanto este estudo é relevante à medida que a educação em saúde pode contribuir para a gestão em saúde, pois permite disseminar a capacidade pedagógica por toda a rede do Sistema Único de Saúde, de forma que se cumpra uma das mais nobres metas formuladas pela saúde coletiva no Brasil: tornar a rede pública de saúde uma rede de ensino-aprendizagem no exercício do trabalho, à medida que é possível construir o processo de formulação e implementação para o SUS.

Este estudo buscou conhecer a produção científica sobre as contribuições da Educação em Saúde como ação estratégica dos modelos de Gestão em Saúde, assim como identificar os modelos de Gestão em Saúde e estabelecer a relação dos modelos de Gestão em Saúde com a Educação em Saúde. A escolha do tema proposto foi devido ao fato que a educação em saúde é um recurso por meio do qual o conhecimento cientificamente produzido no campo da saúde, intermediado pelos profissionais de saúde, atinge a vida cotidiana das pessoas, pois permite conhecer os condicionantes do processo saúde-doença oferecendo alternativas para a adoção de novos hábitos, condutas, e a gestão da saúde.

\section{MÉTODOS}

Trata-se de uma revisão integrativa que de acordo com Mendes et al. (2008) inclui a análise de pesquisas relevantes que dão suporte para a tomada de decisão e a melhoria da prática clínica, possibilitando a síntese do estado do conhecimento de um determinado assunto, além de apontar lacunas do conhecimento que precisam ser preenchidas com a realização de novos estudos. Este método de pesquisa permite a síntese de múltiplos estudos publicados e possibilita conclusões gerais a respeito de uma particular área de estudo.

A revisão integrativa é uma síntese rigorosa de todas as pesquisas relacionadas a uma questão específica, enfocando primordialmente estudos experimentais, comumente ensaios clínicos randomizados. Difere-se de outros métodos de revisão, pois busca superar possíveis vieses em cada 

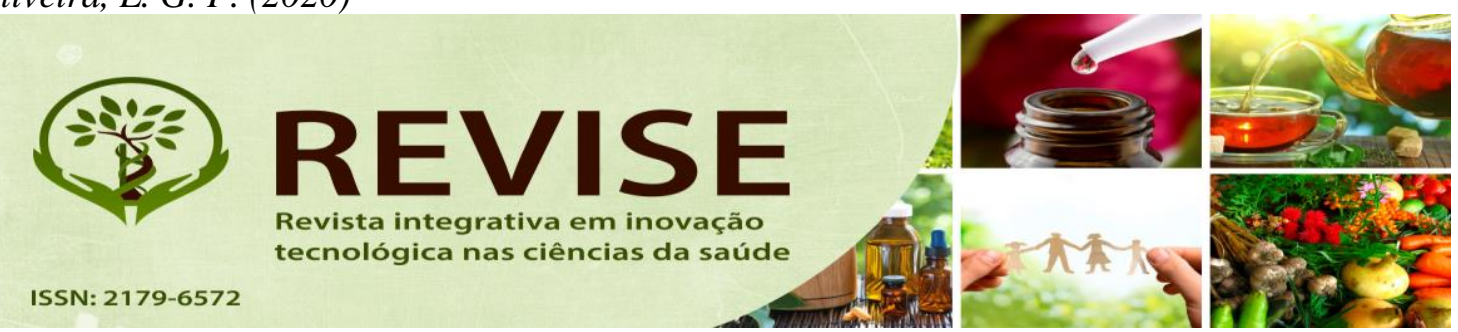

uma das etapas, seguindo um método rigoroso de busca e seleção de pesquisas; avaliação de relevância e validade dos estudos encontrados; coleta, síntese e interpretação dos dados oriundos de pesquisa (SOUZA et al., 2010).

Para o levantamento dos artigos na literatura, realizou-se uma busca nas seguintes bases de dados: Literatura Latino-Americana e do Caribe em Ciências da Saúde (LILACS) e Scientific Electronic Library Online (Scielo), onde foram utilizados, para busca dos artigos, os seguintes descritores e suas combinações nas línguas portuguesa: Educação em Saúde, Gestão em Saúde, Modelos de Gestão em Saúde; e Contribuições para Gestão em Saúde.

Os dados foram coletados no mês de abril a maio do ano de 2019, totalizando 50 dias de coleta de dados. Os critérios de inclusão definidos para a seleção dos artigos foram: artigos publicados em língua portuguesa, apresentados na íntegra que retratassem a temática abordada e artigos publicados e indexados nos referidos bancos de dados nos últimos vinte anos. Foram excluídos os artigos que tiveram publicação anterior ao ano de 2005, em outras línguas e que não estavam alocados nas bases de dados LILACS e Scielo, onde foi realizada a leitura dos títulos, a seguir da leitura dos resumos destas publicações, e por fim a leitura dos trabalhos na íntegra.

As informações extraídas dos artigos basearam a consolidação dos objetivos deste trabalho no que tange a identificação dos modelos de Gestão em Saúde, o estabelecimento da relação dos modelos de Gestão em Saúde com a Educação em Saúde e a posterior de estratégias de Educação em Saúde que contribuem com a eficácia e eficiência da Gestão em Saúde.

\section{GESTÃO EM SAÚDE}

Gestão é um fenômeno universal que ultrapassa a dimensão macro política e a prescrição de atividades e tarefas. Ela envolve escolhas, arbitragens, hierarquização de atos e objetivos, além de envolver valores que orientam a tomada de decisões pelos trabalhadores no cotidiano. Assim, quando se questiona o conceito de gestão é necessário considerar a organização do trabalho coletivo, e a fragmentação de atividades dentro de campos profissionais e a influência da gerência científica nos serviços têm resultado em mudanças (SCHERER et al., 2009).

De acordo com André e Ciampone (2007), no enfoque no setor público de saúde e, mais especificamente, no papel dos gestores de Unidades Básicas de Saúde, atores estes responsáveis pelo 


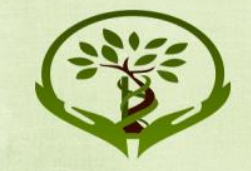

ISSN: 2179-6572

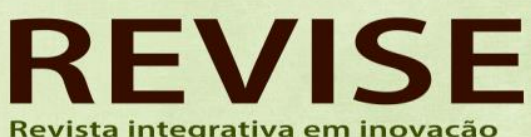

tecnológica nas ciências da saúde

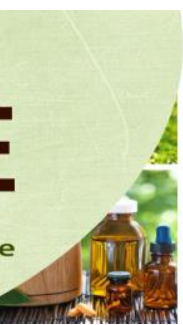

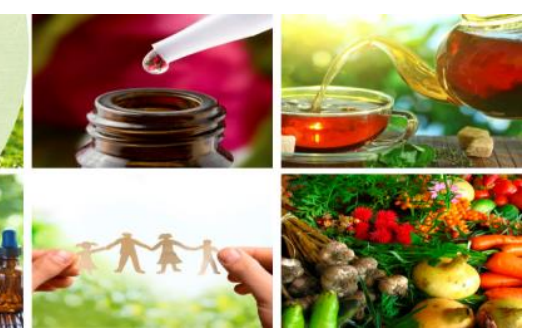

papel de governança e gerenciamento, é importante ressaltar que no nível local eles são reféns de regulamentações que restringem severamente, no plano formal, sua autonomia. Dentre outras limitações, não contam com orçamento próprio para gerir recursos humanos, contratar, descontratar, realizar negociações salariais ou instalar mecanismos de incentivo ou sanção condicionados à produção de metas quanti ou qualitativas. Assim, pode-se afirmar que o sistema continua referendando que os gestores sofram processo de desconcentração, definida como a delegação de responsabilidade sem a equivalente delegação de poder decisório, transferindo-se responsabilidades pela implementação de decisões centralizadas, porém sem a prerrogativa de poder modificá-las conforme a necessidade local.

As organizações de saúde têm a tradição de funcionar com concentração de poder: concentrado nos diretores, nos médicos e nos especialistas. O SUS introduziu a diretriz do controle social, no entanto a ideia de gestão compartilhada foca instâncias do sistema de saúde - conferências e conselhos em municípios, estados e união - e não necessariamente internas aos serviços ou programas. A criação de espaços coletivos, em que equipes de saúde compartilhem a elaboração de planos gerenciais e de projetos terapêuticos, depende ainda de uma ampla reformulação da mentalidade e da legislação do sistema de saúde. As políticas de humanização têm igualmente tentado ampliar o poder dos usuários no cotidiano dos serviços de saúde (CAMPOS; DOMITTI, 2007).

Neste enfoque, o sistema de Gestão em Saúde passa a ser dividido em Modelos de Gestão que vão além do sistema assistencial criando espaços de inter-relação entre várias áreas da gestão, e pontuadas por metas estruturais, éticas, políticas, e culturais.

\section{MODELOS DE GESTÃO}

Ibanes e Neto (2007) destacam que modelo de gestão é produto do subsistema institucional e que representa as principais determinações, vontades e expectativas do gestor, de como as coisas devem acontecer na empresa. Sendo assim, o modelo de gestão é o instrumento de gestão mais significativo - seria o conjunto de normas e princípios que orientam os gestores na escolha das melhores alternativas para levar a empresa a cumprir sua missão com eficácia. Em se tratando das organizações de saúde, independente do tamanho, seus processos são padronizados por regras impostas pelo governo, compradoras de serviços e representantes de classe. A sua mão de obra é 


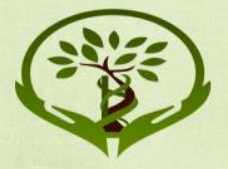

ISSN: 2179-6572

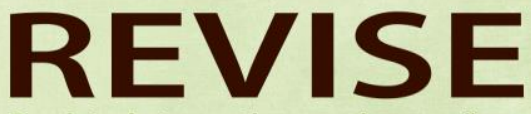

Revista integrativa em inovação tecnológica nas ciências da saúde

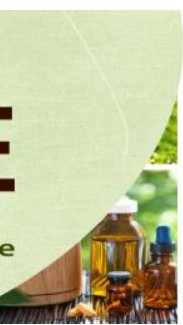

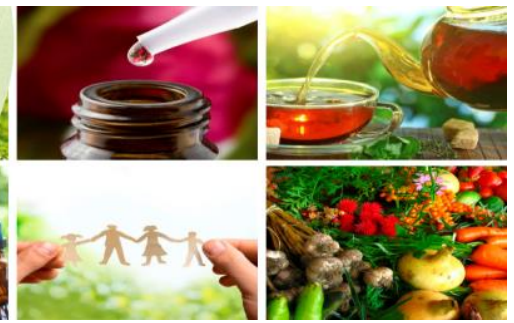

altamente especializada e qualificada. Diante disso estão presentes profissionais de diferentes áreas no mesmo ambiente de trabalho (médicos, enfermeiros, nutricionistas, farmacêuticos, fisioterapeutas, etc.) o que leva a interesses nem sempre convergentes.

Segundo Feuerwerker (2005) durante os primeiros anos de organização do sistema, em suas instâncias de gestão, os principais debates e as polêmicas giraram em torno dos mecanismos de financiamento e de gestão. Havia consenso em relação à necessidade de estabelecer fontes fixas e investimento mínimo indispensável para o financiamento da saúde (luta que acabou desaguando na proposta de emenda constitucional 29, que estabelece investimentos mínimos em saúde para cada uma das três esferas de gestão).

Portanto, considerando a complexidade das organizações de saúde e a relevância dos serviços prestados à sociedade, novos modelos de gestão, a exemplo como descrito por Paim e Teixeira (2006), os Modelo de Atenção à Saúde, tornam-se necessários e imprescindíveis para as organizações alcançarem níveis de excelência na prestação de serviços. Nível de eficiência, eficácia e efetividade que o mercado atual exige e cobra. Neste contexto, como não há um modelo de gestão ideal. As organizações de saúde devem levar em conta sua história, missão, visão e valores, assim como a cultura organizacional. Todos esses fatores tornam uma organização única, o que demanda ações específicas de gestão. Assim são destacados apenas os modelos da Gestão da Qualidade, das Redes de Atenção à Saúde - RAS, da Gestão Estratégica e da Gestão Participativa - Cogestão, como algumas possibilidades para o enorme desafio nesta área (ANDRÉ; CIAMPONE, 2007).

\section{GESTÃO DA QUALIDADE}

Scherer, et al. (2009) destacam que a compilação das dimensões da qualidade é definida a partir de sete pilares: eficácia, eficiência, efetividade, adequação, conformidade, legitimidade, e equidade. Estes autores apontam que as formas atuais de organização e de gestão do trabalho continuam repousando, predominantemente, sobre princípios que sacrificam a subjetividade em nome da rentabilidade e da competitividade. Se por um lado aumenta a produtividade, por outro desagrega coletivos e separa o trabalho do conjunto da vida, agravando as patologias decorrentes do trabalho, comprometendo a qualidade do serviço. O modelo de gestão da qualidade é avaliado a partir de indicadores que incluem rede de informações, desenvolvimento gerencial, regulação e controle da 


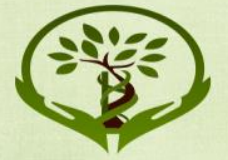

ISSN: 2179-6572

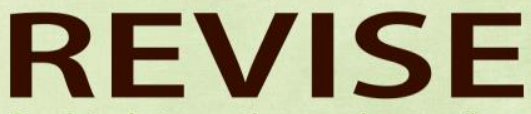

Revista integrativa em inovação tecnológica nas ciências da saúde

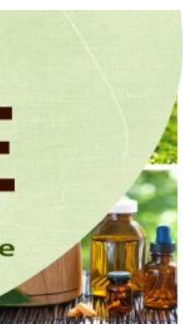

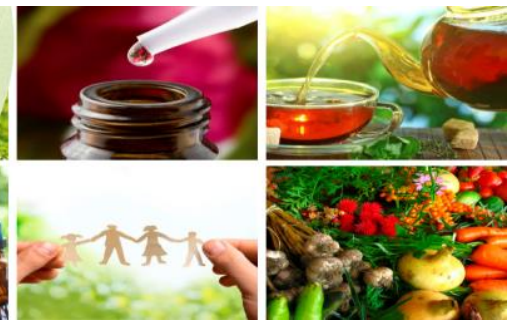

utilização de tecnologias em saúde e controle social, informados por sistemas específicos ligados à vigilância epidemiológica e vigilância sanitária serviços de saúde, tendo como objetivo principal a definição de competências e instrumentos de ação para o Sistema Único de Saúde.

A partir dos anos 80 surgiram duas grandes tendências de gestão da qualidade baseadas principalmente nas normas ISO 9000 e na gestão da qualidade total, sendo que atualmente a principal ferramenta para avaliação de qualidade em saúde o PNGS - Prêmio Nacional de Gestão em Saúde, criado em 2003 a partir da Fundação Nacional da Qualidade (FNQ) e do Controle da Qualidade Hospitalar $(\mathrm{CQH})$ incentivando as instituições de saúde a buscarem melhorias contínuas de seus sistemas de gestão, tendo como base um conjunto de conceitos e os fundamentos que os embasam são: Liderança, Estratégias e Planos, Clientes, Sociedade, Informações e Conhecimentos, Pessoas, Processos e Resultados. A organização que adota esse modelo consegue mapear com clareza seu negócio através da visão sistêmica da organização.

\section{REDES DE ATENÇÃO À SAÚDE - RAS}

De acordo com Rivera e Artmann (2009), a análise da coordenação de serviços de saúde a partir de um modelo construído a partir da lógica do agir comunicativo e baseado na inter-relação entre interdependência, coordenação e integração, cujo eixo estruturante é uma rede dinâmica de conversações que se estabelece entre os distintos atores que interagem no sistema é o ponto chave para a compreensão da lógica na gestão em saúde. Segundo os autores, redes são sistemas organizacionais capazes de reunir indivíduos e instituições, de forma democrática e participativa, em torno de causas afins que supõem atuações colaborativas e se sustentam pela vontade e afinidade de seus integrantes, caracterizando-se como um significativo recurso organizacional para a estruturação social.

No âmbito das organizações de saúde o que se encontram são, segundo Paim e Teixeira (2006), sistemas fragmentados, caracterizados por atenção descontínua, com forte polarização entre o hospital e o ambulatório, sob a hegemonia da atenção hospitalar, e pela ausência de uma coordenação dos pontos de atenção à saúde, de um sistema de inteligência que confira organicidade ao sistema e, normalmente, sem uma população adstrita. Por outro lado, os sistemas integrados estão baseados em três características centrais: a oferta de serviços de forma contínua, por meio de vários 


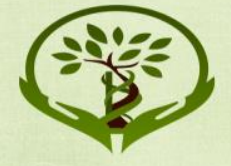

ISSN: 2179-6572

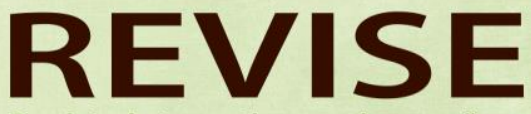

Revista integrativa em inovação tecnológica nas ciências da saúde

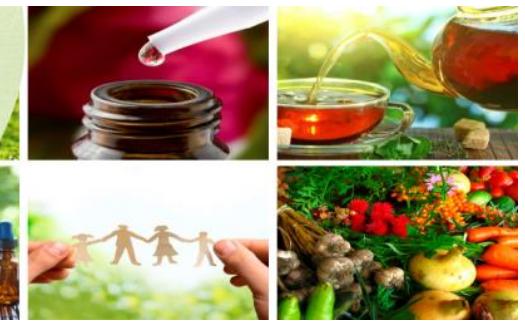

pontos de atenção coordenados; a integração desses pontos de atenção através de sistemas logísticos potentes; e a existência de uma população com necessidades definidas que seja responsabilidade do sistema de saúde. Em relação ao planejamento e gestão, seus traços característicos são a diversificação das abordagens e, especialmente, o desdobramento dos estudos teórico-conceituais em propostas tecnológicas, onde tais propostas vêm se difundindo na prática institucional, gerando uma multiplicidade de relatos, estudos de caso e pesquisas avaliativas, e sua operacionalização tem apontado para a centralidade do sujeito das práticas, isto é, dos gestores e trabalhadores de saúde, além da própria população representada nos conselhos de saúde.

\section{GESTÃO ESTRATÉGICA}

O conceito de gestão estratégica é muito mais amplo e abrangente em relação ao planejamento estratégico que engloba desde as avaliações de diagnósticos e de prontidão, a estruturação do processo de planejamento e formulação de um propósito compartilhado para a organização, a escolha de estratégias, a fixação de metas e desafios, até a atribuição de responsabilidades para o detalhamento dos planos e projetos e a condução e acompanhamento das etapas de sua implantação, processos formais de revisão dos planos para mantê-lo sempre adequados às realidades externas e internas da organização (CAMPOS; DOMITTI, 2007).

Sendo assim, é possível entender a gestão estratégica como um processo sistemático, planejado, gerenciado, executado e acompanhado sob liderança da alta administração da instituição, envolvendo e comprometendo todos os gerentes e responsáveis e colaboradores da instituição. Quando o processo e a metodologia de trabalho são adequados, consegue-se o envolvimento e o comprometimento de todos aqueles que têm uma contribuição efetiva na elaboração e execução das transformações necessárias, onde as pessoas e os processos deixam de ser parte do problema para tornarem-se parte da solução (CECÍLIO, 2005).

Segundo Pedroso (2010), o processo de gestão estratégica é composto por seis etapas:

(1) Análise - nesta etapa está incluída as atividades que envolvem o mapeamento das influências dos stakeholders (que são indivíduos e grupos que afetam ou são afetados pelos resultados da organização e que possuem demandas exigíveis em relação ao seu desempenho), a intenção estratégica da organização (como por exemplo, a análise da missão, visão, valores e cultura 

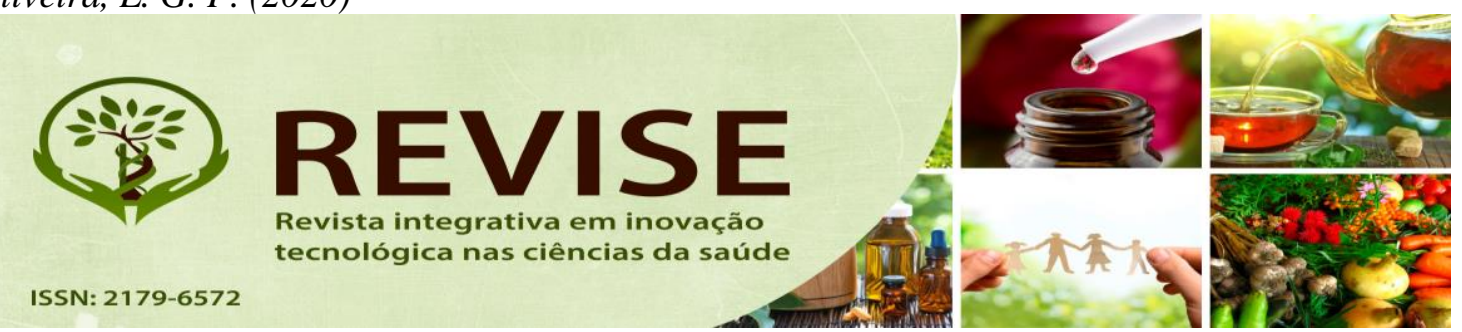

organizacional), a análise do ambiente externo (concorrência, cenário político e econômico), análise do ambiente interno (recursos organizacionais, processos internos, estrutura organizacional);

(2) Formulação - nesta etapa há a definição do posicionamento estratégico e as opções de estratégias;

(3) Implantação - trata-se da execução da estratégia propriamente dita, através de um plano de ação;

(4) Controle - etapa do monitoramento do desempenho estratégico através de indicadores;

(5) Retroalimentação - etapa em que a organização percebe a necessidade de efetivar mudanças ou adaptações em sua trajetória estratégica;

(6) Aprendizagem - envolve processos e práticas que incentivam o aprendizado organizacional em gestão estratégica.

\section{GESTÃO PARTICIPATIVA}

Pedrosa (2008) conceitua gestão participativa como um modo de administrar que inclui o pensar e o fazer coletivo, para que não haja excessos por parte dos diferentes corporativismos e também como uma forma de controlar o estado e o governo. É, portanto, uma diretriz ética e política que visa motivar e educar os trabalhadores. Este modelo é centrado no trabalho em equipe e em colegiados que garantem que o poder seja de fato compartilhado, por meio de análises, decisões e avaliações construídas coletivamente com a participação popular.

A imagem da participação popular em cada ponto do sistema - a gestão participativa - mesmo sendo experimentada por meio da criação de conselhos locais de saúde, conselhos de unidades de saúde (colegiados gestores), plenárias e fóruns populares, colegiados de gestão regional, espaços que legal e necessariamente não se constituem espaços de deliberação e fiscalização da política de saúde, começa a ganhar contornos mais nítidos como pontos de pauta da agenda política do SUS, a partir de dispositivos institucionais, como a criação na estrutura do Ministério da Saúde em 2003, da Secretaria de Gestão do Trabalho e da Educação na Saúde (SGETES) e da Secretaria de Gestão Participativa SGP (designação anterior da atual SGEP) (PEDROSA, 2008).

De acordo com o mesmo autor, a fim de colocar em prática o modelo de gestão participativa, há dois tipos de ação: a organização do espaço coletivo de gestão para permitir o acordo entre desejos 


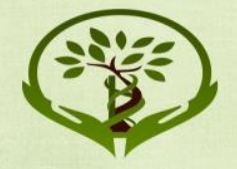

ISSN: 2179-6572

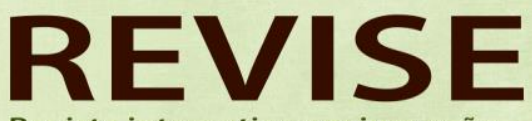

Revista integrativa em inovação tecnológica nas ciências da saúde

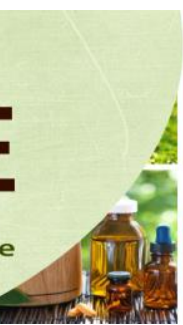

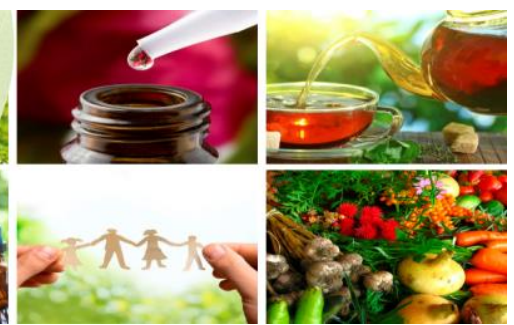

e interesses, tanto dos usuários quanto dos trabalhadores e gestores; e um plano de ação para garantir a participação no cotidiano das unidades de saúde.

\section{RESULTADOS E DISCUSSÃO}

Dos estudos incluídos na presente revisão foi mostrado que a gestão em saúde e assim como os movimentos sociais pela transformação da atenção à saúde possibilitaram a incorporação, em muitos serviços de saúde, de formas de relação com a população bastante participativa e que rompem com a tradição autoritária dominante contribuindo para a gestão em saúde.

No estudo de Ceccim (2005) foi identificada relevância e a viabilidade de disseminar capacidade pedagógica por toda a rede do Sistema Único de Saúde, de forma que se cumpra uma das mais nobres metas formuladas pela saúde coletiva no Brasil: tornar a rede pública de saúde uma rede de ensino-aprendizagem no exercício do trabalho. A disseminação dos Pólos e, por decorrência, de capacidade pedagógica descentralizada gerou novos atores para o SUS, para a sua construção política (e não programática), para a produção da saúde nos atos, nos pensamentos e no desejo de protagonismo pelo SUS, compreendendo seus princípios e diretrizes em uma política de afirmação forte da vida. Esses novos atores, são os atores dos Pólos (tutores, facilitadores e operadores de Educação Permanente em Saúde, entre outros), distribuídos por todo o país, alcançando uma automobilização de pelo menos 20 mil pessoas. Assim como esses atores não existiam e existem agora, a política não existia, apresentou-se inédita e existiu ineditamente, colocando a formação e o desenvolvimento como educação viva, em ato, na saúde.

Já no artigo "Educação Popular em Saúde e Gestão Participativa no Sistema Único de Saúde” de Pedrosa (2008), é realizada uma comparação das proposições e diretrizes, assinalando similitudes entre alguns pontos emergentes dos coletivos da sociedade civil e as ações desenvolvidas pelo Ministério da Saúde, ressaltando os desafios da educação popular e saúde em apresentar características de projeto político de ampliação dos espaços de interlocução entre a gestão do SUS e os movimentos sociais, dispositivo com capacidade de mobilizar a população pelo direito à saúde e pela equidade, e estratégia pedagógica constituinte de sujeitos críticos e propositivos com potencialidade para formulação e deliberação de projetos políticos, no sentido de fortalecer a gestão participativa. 


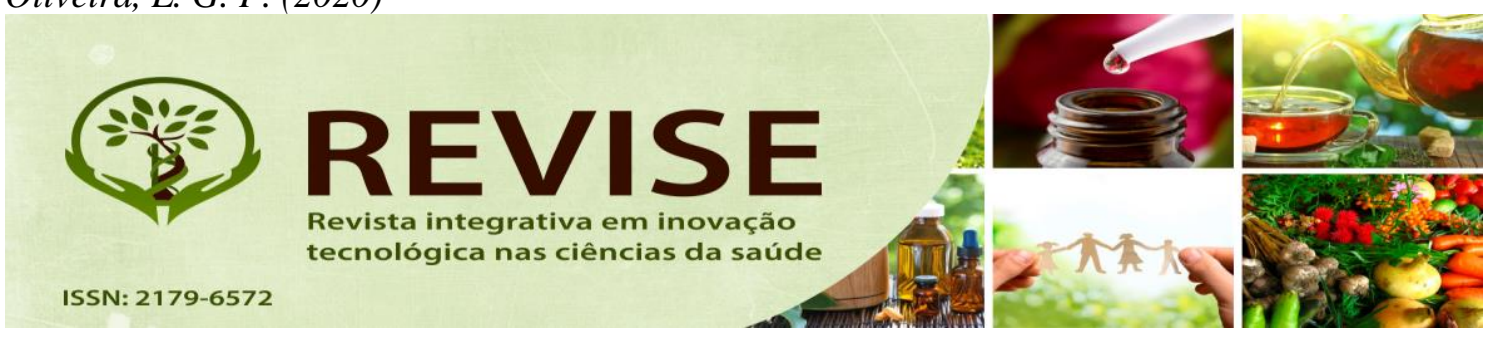

Ele conclui que a educação popular e saúde deve participar do processo de protagonização das classes populares em relação às políticas públicas, pois qualifica a participação de sujeitos sociais e atores políticos que expressem visões de futuro para o Estado e para a Sociedade, haja vista que propostas de inclusão social que objetivam a diminuição das desigualdades não conseguem ser implementadas exclusivamente por meio das estruturas e da burocracia existentes.

Estas reflexões colocam para o campo da educação popular e saúde o desafio de como trabalhar os coletivos sociais para o desenvolvimento de práticas solidárias e de comunicação capazes de suscitar a construção de projetos políticos que ultrapassem a simples tradução das necessidades em demandas que possam ter respostas institucionais, e alcancem o status de diretrizes para a organização social e política do Estado, enfrentando os determinantes sociais da saúde e da doença.

Santorum e Cestari (2011) propõem em seu artigo contribuir com mudanças na formação para o Sistema Único de Saúde (SUS), posto que, mesmo havendo avanços na saúde pública brasileira, ainda há muito a progredir para que os princípios e diretrizes do SUS se materializem nas práticas de atenção, gestão e educação no setor saúde. As autoras concluíram que a formação em saúde tem de problematizar tanto a realidade social quanto a realidade de funcionamento do SUS. Tem de trabalhar a favor da concretização do SUS não como um ideal utópico inatingível, mas como o inédito viável, o sonho possível de um país em que todos e todas tenham acesso aos serviços de saúde com qualidade, em que tenham a possibilidade de um viver saudável, um viver digno.

A educação popular, portanto, pode e deve ser assumida também na universidade para a formação de profissionais que virão a atender os usuários do SUS, possibilitando que os estudantes, no caminho do aprender a conhecer, a fazer, a ser e a viver junto, engajem-se na luta por condições mais justas de vida, a fim de que a população tenha direito à promoção da saúde, à recuperação e ao tratamento de doenças. Enfim, para que ela tenha melhor qualidade de vida.

As limitações para realização desta revisão integrativa foram marcadas pelo entrave de que existem poucos artigos relacionados a esta temática nas plataformas pesquisadas. Espera-se, através dos resultados desta revisão, contribuir com os gestores em saúde para a adoção da educação em saúde como medida de contribuição para a gestão em saúde visto que implica ir além da assistência curativa, significa dar prioridade a intervenções preventivas e promocionais. Um modelo de educação em saúde para o Programa Saúde da Família para a reorganização da atenção básica, a que se propõe a estratégia do PSF, reconhece-se a necessidade de reorientação das práticas de saúde, bem como de 


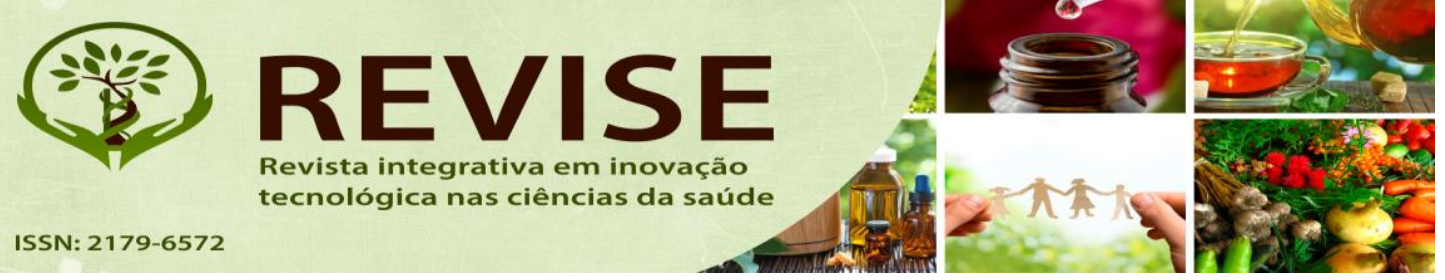

renovação dos vínculos de compromisso e de corresponsabilidade entre os serviços e a população assistida. Ademais, haverá contribuição para o campo científico, podendo a pesquisa constituir como subsídio para outras pesquisas que envolvam ou se aproximem da mesma temática.

\section{CONCLUSÃO}

Os dados alcançados nesta revisão integrativa permitiram conhecer parte da produção científica sobre as contribuições da Educação em Saúde como ação estratégica dos modelos de Gestão em Saúde visto que os entraves na construção deste estudo estiveram concentrados na limitação de artigos que refletem sobre a temática proposta.

A partir do texto, a relação entre a gestão da qualidade e a educação em saúde é a busca por melhorias, através de uma gestão embasada por estratégia, informações, conhecimentos, pessoas, processos, entre outras coisas, portanto a educação em saúde é uma ferramenta indispensável na busca dessas melhorias, através de treinamento, capacitação, aprimoramento dos processos. Em relação as redes de atenção à saúde há uma inter-relação e interação de diversos atores pois relaciona-se com o processo de educação em saúde através da diversificação das abordagens, proporcionando novos aprendizados para gestores, trabalhadores e população.

No tocante à gestão estratégica, através de pessoas e processos, a educação em saúde torna-se indispensável em cada uma das etapas (não só na etapa Aprendizagem) para que se obtenha a capacitação de todas as pessoas envolvidas, bem como o aprimoramento em todas as etapas do processo. Já na gestão participativa, a educação em saúde constitui-se de sujeitos críticos e propositivos, com potencial para formulação e deliberação, conforme já apresentados na seção Resultados e Discussão.

Com este estudo foi possível identificar os modelos de Gestão em Saúde e sua aplicabilidade aos gestores nos dias atuais, e foi possível estabelecer a relação dos modelos de Gestão em Saúde com a Educação em Saúde tendo em vista que esta é um saber importante para a construção da participação popular, servindo não apenas para a criação de uma nova consciência sanitária, como também para uma democratização mais radical das políticas públicas. Não é apenas um estilo de comunicação e ensino, mas também um instrumento de gestão participativa de ação social, haja vista que permite fazer promoção da saúde. Uma das estratégias para isto é apoiar iniciativas de formação

Educação em Saúde. Revista Revise. vol. 3, Fluxo Contínuo, Dossiê Gestão em Saúde, p.169-182. 


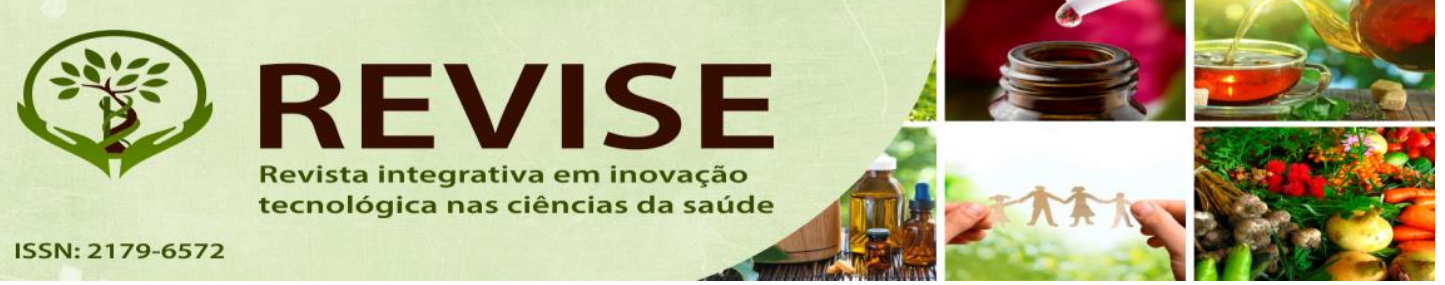

profissional que busquem reorientar as atitudes dos trabalhadores de saúde na relação com a população.

\section{REFERÊNCIAS}

ALVES, Vania Sampaio. Um modelo de educação em saúde para o Programa Saúde da Família: pela integralidade da atenção e reorientação do modelo assistencial. Interface-Comunicação, Saúde, Educação, v. 9, n. 16, set. 2004/fev. 2005, (p. 39-52). Disponível em: http://www.scielo.br/pdf/icse/v9n16/v9n16a04.pdf. Acesso em: 03/06/2019.

ANDRÉ, Adriana Maria; CIAMPOME, Maria Helena Trench. Competências para a gestão de Unidades Básicas de Saúde: percepção do gestor. Revista da Escola Enfermagem da USP, v. 41(Esp), 2007, (p. 835-40). Disponível em:

http://www.scielo.br/pdf/reeusp/v41nspe/v41nspea16.pdf. Acesso em: 12/05/2019.

BESEN, Candice Boppré, et. al. A estratégia saúde da família como objeto de educação em saúde. Revista Saude soc. [online], v.16, n.1, 2007, (p. 57-68). Disponível em:

https://www.scielo.br/scielo.php?pid=S0104-12902007000100006\&script=sci_abstract\&tlng=pt. Acesso em: 03/06/2019.

CAMPOS, Gastão Wagner de Souza; DOMITTI, Ana Carla. Apoio matricial e equipe de referência: uma metodologia para gestão do trabalho interdisciplinar em saúde. Caderno de Saúde Pública, v. 23, n. 2, fev. 2007, (p. 399-407). Disponível em: http://www.scielosp.org/pdf/csp/v23n2/16.pdf. Acesso em: 12/05/2019.

CECCIM, Ricardo Burg. Educação Permanente em Saúde: descentralização e disseminação de capacidade pedagógica na saúde. Revista Ciência e saúde coletiva, v.10, n. 4, out./dez. 2005. Disponível em: http://www.scielosp.org/scielo.php?script=sci_arttext\&pid=S141381232005000400020\&lng=pt. Acesso em: 08/05/2019.

CECÍLIO, Luís Carlos de Oliveira. É possível trabalhar o conflito como matéria-prima da gestão em saúde?. Caderno de Saúde Pública, v. 21, n. 2, mar./abr. 2005, (p. 508-516). Disponível em: http://www.scielo.br/pdf/csp/v21n2/17.pdf. Acesso em: 12/05/2019.

FEUERWERKER, Laura. Modelos tecnoassistenciais, gestão e organização do trabalho em saúde: nada é indiferente no processo de luta para a consolidação do SUS. Inteface (Botucatu), v. 9, n. 18, 2005, (p. 489-506). Disponível em: https://www.scielo.br/scielo.php?pid=S141432832005000300003\&script=sci_abstract\&tlng=pt. Acesso em: 12/05/2019.

IBANES, Nelson; NETO, Gonzalo Vecina. Modelos de Gestão e o SUS. Ciência \& Saúde Coletiva, v. 12(Sup), 2007, (p. 1831-1840). Disponível em: http://www.scielo.br/pdf/csc/v12s0/06.pdf. Acesso em: 10/05/2019. 


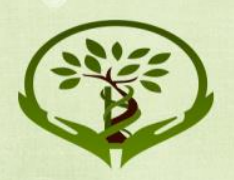

ISSN: 2179-6572

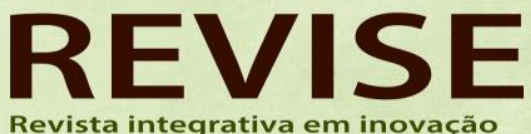

Revista integrativa em inovação tecnológica nas ciências da saúde

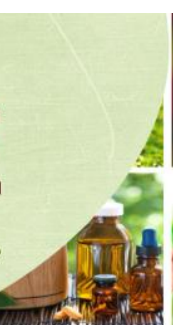

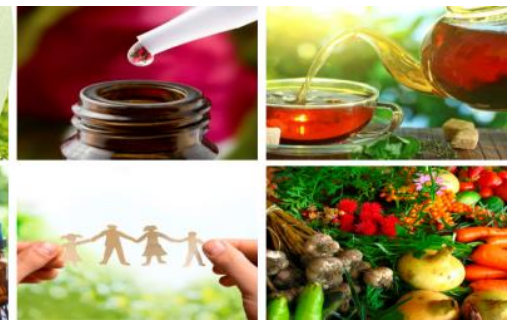

MENDES, Karia Dal Sasso, et. al. Revisão integrativa: método de pesquisa para a incorporação de evidências na saúde e na enfermagem. Texto contexto Enfermagem. v. 17, n. 4, oct./dec. 2008, (p. 758-64). Disponível em: http://www.scielo.br/pdf/tce/v17n4/18.pdf. Acesso em: 24/05/2019.

PAIM, Jaimilson Silva; TEIXEIRA, Carmen Fontes. Política, planejamento e gestão em saúde: balanço do estado da arte. Revista de Saúde Pública, v. 40, n. Esp, 2006, (p. 73-8). Disponível em: http://www.scielo.br/pdf/rsp/v40nspe/30625. Acesso em: 10/05/2019.

PEDROSA, José Ivo dos Santos. Educação Popular em Saúde e Gestão Participativa no Sistema Único de Saúde. Rev. APS, v. 11, n. 3, jul./set. 2008, (p. 303-313). Disponível em: http://aps.ufjf.emnuvens.com.br/aps/article/view/344/122. Acesso em: 10/05/2019.

PEDROSO, Marcelo Caldeira. Um modelo de gestão estratégica para serviços de saúde. Tese de Doutorado, Curso de Medicina, Departamento de Medicina Preventiva. Universidade de São Paulo, São Paulo, 2010. Disponível em:

www.teses.usp.br/teses/disponiveis/5/5137/.../MarceloCaldeiraPedroso.pdf. Acesso em: $10 / 05 / 2019$.

RIVERA, Francisco Javier Uribe; ARTMANN, Eliabeth. Planejamento e gestão em saúde: histórico e tendências com base numa visão comunicativa. Revista Ciência \& Saúde Coletiva, v. 15, n. 5, 2010, (p. 2265-2274). Disponível em: http://www.scielosp.org/pdf/csc/v15n5/v15n5a02.pdf. Acesso em: $10 / 05 / 2019$.

SANTORUM, Juliana Acosta; CESTARI, Maria Elisabeth. A educação popular na práxis da formação para o SUS. Trab. educ. saúde (Online), v. 9, n. 2, oct. 2011, (p. 223-240). Disponível em: http://www.scielo.br/pdf/tes/v9n2/04.pdf. Acesso em: 03/06/2019.

SCHERER, Magda Duarte dos Anjos, et. al. Trabalho coletivo: um desafio para a gestão em saúde. Revista de Saúde Pública, v. 43, n. 4, 2009, (p. 721-25). Disponível em:

http://www.scielo.br/pdf/rsp/v43n4/90.pdf. Acesso em: 03/06/2019.

SOUZA, Marcela Tavares de Souz, et. al. Revisão integrativa: o que é e como fazer. Revista Einstein, v. 8 (1 Pt 1), 2010, (p. 102-6). Disponível em:

http://astresmetodologias.com/material/O_que_e_RIL.pdf. Acesso em: 03/06/2019. 